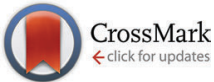

Cite this: J. Mater. Chem. B, 2017, 5, 1028

Received 19th October 2016, Accepted 11th December 2016

DOI: $10.1039 / c 6 t b 02732 f$

www.rsc.org/MaterialsB

\title{
Effective control of the intrinsic DNA morphology by photosensitive polyamines $\uparrow$
}

\author{
M. Deiana, ${ }^{a}$ Z. Pokladek, ${ }^{b}$ K. Matczyszyn, ${ }^{\star a}$ P. Mlynarz, $^{\text {b }}$ M. Buckle ${ }^{c}$ and M. Samoc ${ }^{a}$
}

Non-viral vectors for gene therapy such as DNA-cationic probe complexes offer important bio-safety advantages over viral approaches, due to their reduced pathogenicity, immunogenicity and cytotoxicity. In the present study we examine two polycationic water-soluble azobenzene derivatives (bis-Azo-2N and bis-Azo-3N) containing different linear unsubstituted polyamine moieties and we demonstrate the ability of such photochromes to destabilize the intrinsic B-DNA secondary structure in a concentrationdependent manner. Furthermore, through a detailed series of biophysical experiments, varying the photochrome conformation, temperature, salt and DNA concentration, we provide a detailed insight into the azobenzene-DNA binding pathway $\left(K_{\mathrm{a}}\right.$ : bis-Azo-2N(trans)-DNA $=5.3 \pm 0.3 \times 10^{4} \mathrm{M}^{-1}$, $K_{\mathrm{a}}$ : bis-Azo-2N(cis)-DNA $=2.6 \pm 0.2 \times 10^{4} \mathrm{M}^{-1}, K_{\mathrm{a}}$ : bis-Azo-3N(trans)-DNA $=7.1 \pm 0.4 \times 10^{4} \mathrm{M}^{-1}$ and $K_{\mathrm{a}}$ : bis-Azo-3N(cis)-DNA $=5.1 \pm 0.4 \times 10^{4} \mathrm{M}^{-1}$ ) establishing the versatility of such materials as promising candidates for use in non-viral gene delivery systems.

\section{Introduction}

Gene-based therapy is a pivotal method to treat pathological conditions by altering directly a patient's genome. ${ }^{1}$ It provides a unique strategy to cure not only inherited genetic disorders but also a wide range of inflammatory, infectious and metabolic diseases by delivering a therapeutic gene material and its associated regulatory elements into nuclei. ${ }^{2}$ It turns out that the development of safe, specific, effective and biocompatible carrier vehicles represents a fundamental engineering challenge to ensure success in clinical trials. ${ }^{3}$ Although viral vectors have substantially advanced the field of gene therapy, severe drawbacks, including immunogenicity, carcinogenesis, broad tropism, limited DNA packing capacity and issues in vector production, have limited their effective applications. ${ }^{4}$ Non-viral vectors possess the potential to address and circumvent many of these limitations, particularly with respect to pathogenicity, bio-safety, low cost and ease of production. ${ }^{4 b}$ Within this framework, chemical vectors, mostly

\footnotetext{
${ }^{a}$ Advanced Materials Engineering and Modelling Group, Faculty of Chemistry, Wroclaw University of Science and Technology, Wyb. Wyspianskiego 27, 50-370 Wroclaw, Poland. E-mail: katarzyna.matczyszyn@pwr.wroc.pl

${ }^{b}$ Department of Bioorganic Chemistry, Faculty of Chemistry, Wroclaw University of Science and Technology, Wyb. Wyspianskiego 27, 50-370 Wroclaw, Poland ${ }^{c}$ LBPA, ENS Cachan, CNRS Université Paris-Saclay, 61 Avenue du Président Wilson, F-94235, Cachan, France

$\dagger$ Electronic supplementary information (ESI) available: Synthesis and characterization of the photochromes (p. S2), Hill plots (p. S4), Van't Hoff plots (p. S5), infrared spectroscopy (p. S5), ellipticity variations (p. S11), analysis of the effect of changes in salt concentration on the equilibrium binding constant (p. S12), and calculation of the intrinsic polyamine charges (p. S12). See DOI: 10.1039/c6tb02732f
}

including cationic molecules, have emerged as one of the major non-viral DNA delivery tools and have been widely used to transfect various cell types and deliver cancer vaccines. ${ }^{5}$ DNA-cationic molecule complexes involving electrostatic and hydrophobic forces form uniquely compacted structures called catioplexes and the transfection efficiency depends on the overall geometric shape, the number of positive charges and linker bondage. ${ }^{4 b, 5 g}$ Moreover, complexation between the vectors and DNA plays a crucial role in determining the efficiency of gene transfection since the nature of the physicochemical and biophysical response of the adducts determines the modes of cellular entry. ${ }^{6}$ These features prompted us to investigate whether the concept of innovative and smart carrier vehicles suitable for non-viral gene transfer could be enriched with an additional advantage by application of new photoactive cationic materials. ${ }^{7}$ In this framework, polyamines play a pivotal role since their structure is easily amenable to chemical modification through insertion of reactive moieties and their ability to induce DNA condensation to nanoparticles is well-known. ${ }^{5 g}$ Polyamines have been shown to possess reduced toxicity and to facilitate the transport of oligonucleotides in breast cancer cells. ${ }^{5 g}$ Moreover, it is known that the presence of high concentrations of polyamines leads to resolubilization of the complexed DNA in its free form through osmotic stress or charge reversal mechanisms. ${ }^{5 g}$ We have recently revealed the DNA binding mechanism of two mono-substituted azobenzene based-polyamine units and demonstrated that the changes in the shape occurring upon photo-isomerization permitted us to control, in a reversible way, the intrinsic DNA morphology (B-to-A transition). ${ }^{7 e}$ Along this line, the photoisomerization process of the azobenzene 

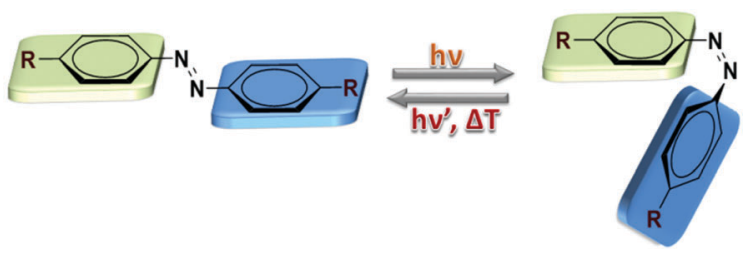

bis-Azo-2N R= $\mathrm{CONHCH}_{2} \mathrm{CH}_{2} \mathrm{NH}_{2}$ bis-Azo-3N R=CONHCH${ }_{2} \mathrm{CH}_{2} \mathrm{NHCH}_{2} \mathrm{CH}_{2} \mathrm{NH}_{2}$

Fig. 1 Structures and interconversion pathways of the photosensitive polyamines bis-Azo-2N and bis-Azo-3N in their both relevant forms: trans and cis.

structure was investigated in depth by our group through nonlinear optics (NLO) and quantum mechanics in both solutions and liquid crystalline phases. ${ }^{7 f-i}$ In this study, we report on the synthesis and characterization of photoswitchable DNA binding of two bis-substituted polycationic, water-soluble azobenzene derivatives, denoted as bis-Azo-2N and bis-Azo-3N (Fig. 1), containing different linear unsubstituted polyamine moieties and we demonstrate that their binding leads to stronger changes in the DNA structure if compared to the mono-substituted compounds. In particular, we show that the changes in the intrinsic DNA morphology are strongly dependent on the [azobenzene]/[DNA] ratio used and that, in sharp contrast to our previous results, ${ }^{7 e}$ the bis-substituted photochromes, once bound, lack the ability to reversibly modulate the chirality of the biopolymer. Moreover, a detailed series of biophysical experiments varying the photochrome conformation, temperature, salt and DNA concentration provided an exhaustive description of the azobenzene-DNA structure-activity relationship. Our structural analysis of the photochrome-DNA interactions should help to gain insights into the nature of this biologically important in vitro complexation serving as a proof of concept in the design of multivalent smart photoswitchable vectors for targeted gene delivery.

\section{Experimental}

\section{Apparatus}

The UV-Vis absorption spectra were recorded on a Perkin Elmer Lambda 20 UV-Vis spectrometer. An electronic thermostated water bath (PTP-1 Peltier system DBS) was used for controlling the temperature. Fluorescence analyses were carried out using a Hitachi F-4500 spectrofluorometer equipped with a xenon lamp and a thermostated bath. Circular dichroism spectra were recorded using a Jasco J-815 spectropolarimeter (Jasco Inc, USA) equipped with the Jasco Peltier-type temperature controller (CDF-426S/15). The infrared spectra were collected on the diamond crystal surface under vacuum $(<1 \mathrm{hPa})$ using a Bruker Vertex70v FT-IR spectrometer.

\section{Reagents and preparation of stock solutions}

Common reagent-grade chemicals were used without further purification. The stock solution of deoxyribonucleic acid sodium salt from salmon testes (DNA $\approx 2000 \mathrm{bp}$ ), purchased from Sigma Aldrich Chem. Co., was prepared by dissolving an appropriate amount of solid DNA powder in $10 \mathrm{mM}$ sodium cacodylate buffer (pH 7.2). Stock solution was stored at $4{ }^{\circ} \mathrm{C}$ for 24 hours with occasional stirring and was used after no more than 3 days. The appropriate DNA solution concentrations were determined by absorption spectrometry according to the absorbance at $260 \mathrm{~nm}$ and expressed in bp $\left(\varepsilon_{260}=13200 \mathrm{M}^{-1} \mathrm{~cm}^{-1}\right)$. The purity of the DNA was checked by monitoring the ratio of the absorbance at 260 and $280 \mathrm{~nm}$ and at 260 and $230 \mathrm{~nm}$ giving values higher than 1.8 and 2.2, respectively, thus showing the DNA to be sufficiently free from protein impurities. The bis-Azo-2N and bis-Azo-3N stock solutions were prepared by dissolving appropriate amounts of the azobenzene derivatives in double distilled water to a final concentration of $0.5 \mathrm{mM}$. The stock solutions were stored and protected from light by wrapping the vials with aluminium foil. The reported data are at least the average values of three trials. The quantitative data analysis reported throughout the whole paper took into account the trans: cis $(80: 20)$ and cis:trans $(25: 75)$ ratio derived for each photochrome.

\section{UV-Vis measurements}

The UV-Vis absorption spectra were recorded at 298, 301, 305 and $309 \mathrm{~K}$ keeping the concentration of the azobenzene derivatives constant and adding incremental amounts of DNA. After addition of DNA to the azobenzene solutions, the resulting system was subjected to UV-Vis analysis in the 200-600 nm range. In order to resolve the contribution from bis-Azo-2 and bis-Azo-3 exclusively, the spectrum of the equimolar solution of DNA added was subtracted in the full measured range. The photoinduced isomerization reactions of bis-Azo-2N and bis-Azo-3N were performed by using a high pressure Oriel $\mathrm{Hg}$ lamp equipped with interference filters at 313 and $436 \mathrm{~nm}$. The resulting light power density was $\sim 0.41 \mathrm{~mW} \mathrm{~cm}^{-2}$ at $313 \mathrm{~nm}$ (trans-cis) and $\sim 1.04 \mathrm{~mW} \mathrm{~cm}^{-2}$ at $436 \mathrm{~nm}$ (cis-trans).

\section{Competition experiment}

The competitive interaction between Ethidium bromide (EtBr) and bis-Azo-2N and bis-Azo-3N with DNA was studied by adding different amounts of bis-Azo-2N and bis-Azo-3N to the EtBr-DNA solution. Fluorescence spectra of the mixture were recorded at $298,301,305$ and $309 \mathrm{~K}$ in the range of 540-800 $\mathrm{nm}$ using an excitation wavelength of $530 \mathrm{~nm}$.

\section{Circular dichroism measurements}

CD spectra were recorded at $298 \mathrm{~K}$ in the wavelength range of 200-600 nm at different azobenzene/DNA molar ratios and keeping constant the DNA concentration. Before use, the optical chamber of the $\mathrm{CD}$ spectrometer was deoxygenated with dry nitrogen and was held under a nitrogen atmosphere during the measurements. Each spectrum was averaged from five successive accumulations and the buffer contribution has been subtracted.

\section{FT-IR spectroscopic measurements}

The infrared spectra were recorded, after incubation of the salmon sperm DNA/azobenzene solution, via the Attenuated Total Reflection (ATR) method, in the spectral range $4000-400 \mathrm{~cm}^{-1}$ with a resolution of $4 \mathrm{~cm}^{-1}$ and accumulation of 64 scans, and 
transformed into absorbance spectra using OPUS software. Spectra subtraction [(ds-DNA solution + azobenzene) - azobenzene solution] was performed to make sure that the observed changes in the DNA shift peak position were attributable exclusively to ligand interactions. The plots of the relative intensity $(R)$ of several bands of DNA caused by in-plane vibrations of base pairs and the stretching vibration of the $\mathrm{PO}_{2}$ versus the azobenzene concentrations were obtained by carrying out normalization of bands using $R=I_{\mathrm{i}} / I_{962}$ where $I_{\mathrm{i}}$ is the intensity of the absorption band at $\mathrm{i} \mathrm{cm}^{-1}$ for pure salmon testes DNA and its complex with different concentrations of azobenzene, and $I_{962}$ is the intensity band of the $962 \mathrm{~cm}^{-1}$ internal reference band. ${ }^{5 d}$

\section{Results and discussion}

\section{UV-Vis absorption spectra of azobenzene-DNA adducts}

The absorption spectra of the azobenzene derivatives consisted mainly of two main charge transfer (CT) bands: one of strong intensity located in the UV $\left(\lambda_{\max } \approx 330 \mathrm{~nm}\right)$ and the other, of weaker intensity, in the visible spectral region $\left(\lambda_{\max } \approx 450 \mathrm{~nm}\right)$.

When DNA was added to bis-Azo-2N and bis-Azo-3N, in both their isomeric forms, a noticeable hypochromic effect was detected (Fig. 2 upper panel). This behaviour is typical of molecules intercalating between DNA bases, the magnitude of the effect being related to the strength of the intercalative interaction. ${ }^{7 e, 8}$ The $\pi-\pi^{*}$ transition band of bis-Azo-2N and bis-Azo-3N in trans conformation in the presence of DNA undergoes 36 and 39\% hypochromicity and a red shift of 2 and $4 \mathrm{~nm}$, respectively. The differences in the intercalative binding strength between the two conjugates may be related to the regiochemical distribution of charges along the polyamine backbone. Indeed, the increase in the number of positive charges at nitrogens as well as the difference in the number of methylene spacers have an impact on the azobenzene derivatives' capacity to intercalate DNA. ${ }^{7 e}$ bis-Azo-2N and bis-Azo-3N in the cis form, under the same experimental conditions, gave rise to 23 and $28 \%$ hypochromicity and a bathochromic effect of 4 and $6 \mathrm{~nm}$, respectively. The observed changes can be ascribed to the planarity of the trans form which, having a marked hydrophobic character, makes it suitable as a DNA intercalator, whereas the non-planarity of the bent cis form being more hydrophilic decreases to some extent its intercalative ability. It is worth noting that these findings are in good agreement with those previously reported by us for the interaction of monosubstituted Azo-3N with DNA.

\section{UV-Vis quantitative data analysis}

Exploiting the absorption changes arising upon DNA addition to bis-Azo-2N and bis-Azo-3N, it was possible to quantitatively compare the binding affinity of the conjugates in both their isomeric forms with DNA. Thus a multi-binding data analysis was performed allowing calculation of the equilibrium association binding constants $\left(K_{\mathrm{a}}\right)$ using the Benesi-Hildebrand equation: ${ }^{9}$

$$
\frac{1}{\Delta A}=\frac{1}{\Delta A_{\max }}+\frac{1}{K_{\mathrm{a}}\left(\Delta A_{\max }\right)} \times \frac{1}{[\mathrm{DNA}]}
$$
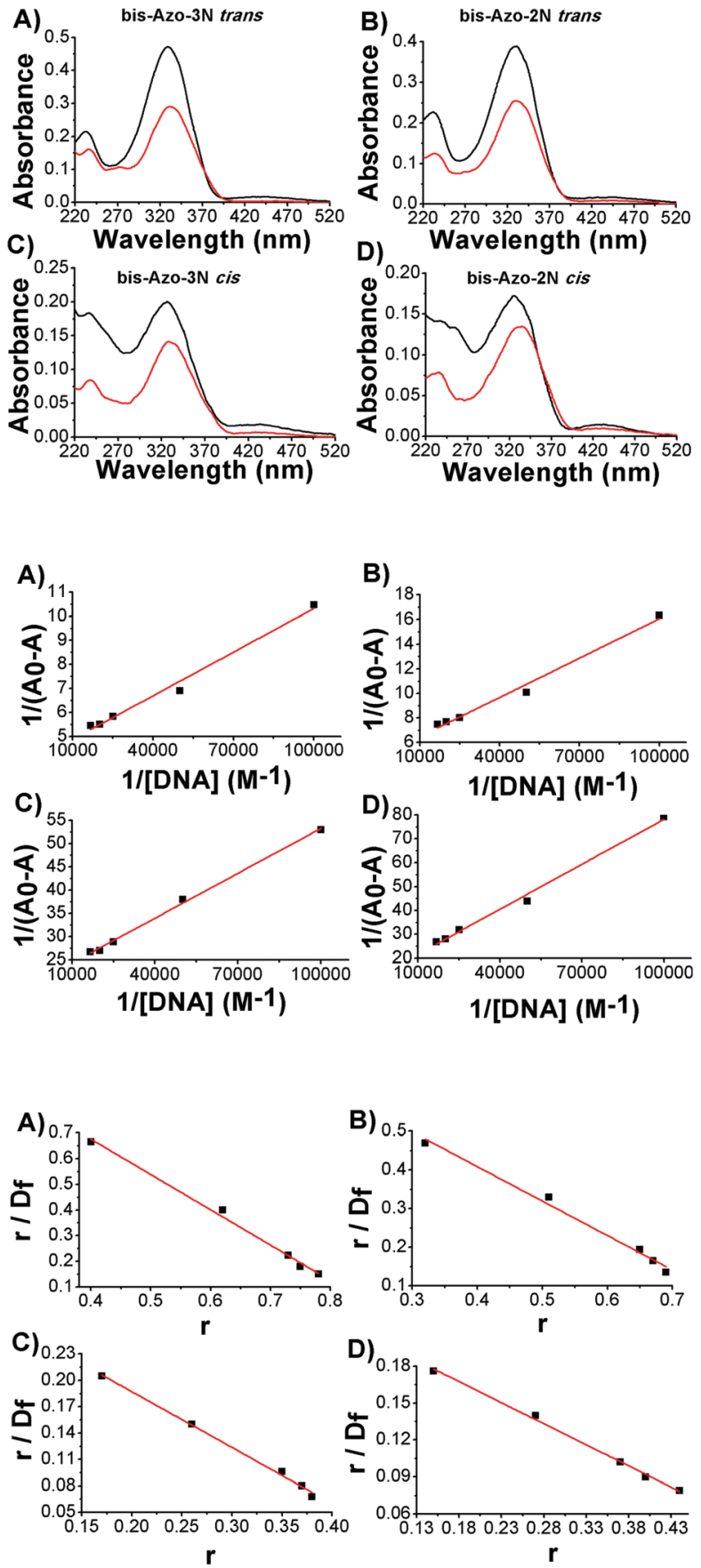

Fig. 2 Upper panel: (A) Absorption spectra of bis-Azo-3N trans, (B) bis-Azo-2N trans, (C) bis-Azo-3N cis and (D) bis-Azo-2N cis in the free (black line) and bound form (red line) at the saturation point. The concentration of bis-Azo-3N and bisAzo-2N was $2 \times 10^{-5} \mathrm{M}$ in $10 \mathrm{mM}$ sodium cacodylate trihydrate (pH 7.2). The DNA concentration was $6 \times 10^{-5} \mathrm{M}$. Central panel: Benesi-Hildebrand plots of $1 /\left(A-A_{0}\right)$ against 1/[DNA] for (A) bis-Azo-3N(trans)-DNA, (B) bis-Azo-2N(trans)DNA, (C) bis-Azo-3N(cis)-DNA and (D) bis-Azo-2N(cis)-DNA systems at $298 \mathrm{~K}$. $A_{0}$ and $A$ are the absorbance values of the azobenzene derivatives in the absence as well as in the presence of DNA, respectively. The DNA concentration was 0 , 10, 20, 40, 50 and $60 \mu \mathrm{M}$. Lower panel: Scatchard plots for (A) bis-Azo3N(trans)-DNA，(B) bis-Azo-2N(trans)-DNA，(C) bis-Azo-3N(cis)-DNA and (D) bis-Azo-2N(cis)-DNA systems at $298 \mathrm{~K} . r$ is the number of moles of ligand bound per mole of nucleic acid (referred to as the concentration of the complex formed) and $D_{\mathrm{f}}$ is the molar concentration of the free ligand (concentration of the free photochrome in solution corrected by the trans/cis ratio upon duplex complexation). The DNA concentration was $0,10,20,40,50$ and $60 \mu \mathrm{M}$. 
where $\Delta A$ is the difference between the absorbance of the conjugates in the absence and in the presence of DNA and $\Delta A_{\max }$ is the final absorbance of the Azo-DNA adducts which indicates saturation of interaction.

When small molecules bind to a set of equivalent sites on a macromolecule, the equilibrium association binding constants $\left(K_{\mathrm{b}}\right)$ and the number of molecules bound per polynucleotide $(n)$ can be examined according to the Scatchard analysis based on the following equation: ${ }^{10}$

$$
\frac{r}{D_{\mathrm{f}}}=n K_{\mathrm{b}}-r K_{\mathrm{b}}
$$

where $r$ is the number of mole of ligand bound per mole of macromolecule (i.e. the relative concentration of the complex formed between each photochrome isomer and the duplex taking into account the trans/cis ratio), $D_{\mathrm{f}}$ is the molar concentration of the free ligand (i.e. the absolute concentration of the photochrome in its peculiar configuration $(+/-$ UV) free in solution upon duplex complexation) and $n$ is the apparent number of the binding sites. The corresponding results from eqn (1) and (2) are shown in Table 1.

The association constant values calculated by using different binding data analyses show a relatively high binding affinity of the azo compounds to duplex DNA (Fig. 2 central and lower panels). The order of affinity of Azo-DNA complexes was found as: bis-Azo-3N trans $>$ bis-Azo-2N trans $>$ bis-Azo-3N cis $>$ bis-Azo-2N cis. It is important to stress that the magnitude of the binding constants found for the Azo-DNA adducts matches well with those found for well-known intercalators indicating that the intercalation process is most likely the dominant mode of the interaction between the azobenzene derivatives and DNA. $^{7 e, 11}$ Furthermore, the binding isotherms, obtained by Scatchard analysis (Fig. 2 lower panel), were linear indicating no deviations from Clark's model and the single binding site $n$ pointed out the relative high binding selectivity of the photochromes towards the biopolymer reactive sites. ${ }^{12}$ It is worth noting that the reported values of $n$ must be considered apparent for the following reasons:

(i) the association constants are calculated by a single-site binding model,

(ii) the observable physical quantity used, i.e. absorption, is proportional to the concentration (extensive variable) and not to the mole fraction (intensive variable e.g. fluorescent polarization) which do not allow for an overall calculation of the binding parameters.

In order to better elucidate if cooperative binding is taking part in the association process a Hill analysis was performed

Table 1 Association constants and number of interacting sites for the photochrome-DNA complexes at $298 \mathrm{~K}$

\begin{tabular}{lllll}
\hline & $\begin{array}{l}K_{\mathrm{a}} \mathbf{M}^{-1} \\
(\text { eqn }(1))\end{array}$ & $\begin{array}{l}K_{\mathrm{b}} \mathbf{M}^{-1} \\
(\text { eqn }(2))\end{array}$ & $\begin{array}{l}n \\
(\text { eqn }(2))\end{array}$ & $\begin{array}{l}n \\
(\text { eqn }(3))\end{array}$ \\
\hline bis-Azo-2N trans & $5.3 \pm 0.3 \times 10^{4}$ & $9.0 \pm 0.1 \times 10^{4}$ & 0.96 & 1.03 \\
bis-Azo-2N cis & $2.6 \pm 0.2 \times 10^{4}$ & $3.4 \pm 0.2 \times 10^{4}$ & 0.93 & 0.99 \\
bis-Azo-3N trans & $7.1 \pm 0.4 \times 10^{4}$ & $1.3 \pm 0.1 \times 10^{5}$ & 0.99 & 1.00 \\
bis-Azo-3N cis & $5.1 \pm 0.4 \times 10^{4}$ & $6.4 \pm 0.2 \times 10^{4}$ & 0.95 & 0.99
\end{tabular}
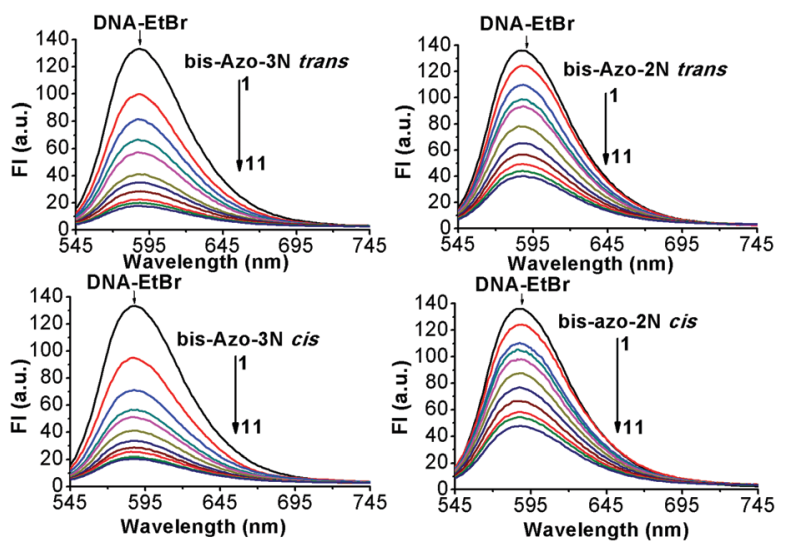

Fig. 3 Fluorescence emission spectra of the competition between EtBr-DNA complex $\left(\lambda_{\text {exc }}: 530 \mathrm{~nm}\right.$ ) and the photochromes treated with: $0,2.5,5,7.5$, $10,15,20,25,30,35$ and $40 \mu \mathrm{M}$ (curves 1-11) of azobenzene derivatives. [EtBr]: $10 \mu \mathrm{M}$ and [DNA]: $40 \mu \mathrm{M}$.

using eqn (3): ${ }^{12}$

$$
\log \left[\frac{B}{\left(B_{\max }-B\right)}\right]=n\left[\log \left(L_{\mathrm{f}}\right)\right]-\log \left(K_{\mathrm{d}}\right)
$$

where $B$ and $B_{\max }$ are the bound ligand and the total receptor concentration, respectively, $L_{\mathrm{f}}$ is the free ligand concentration and $K_{\mathrm{d}}$ is the equilibrium dissociation constant. The obtained values are listed in Table 1.

The straight line achieved using eqn (3) (ESI, $\dagger$ Fig. S1A-D) confirms the applicability of this model to our data. As shown in Table 1, the average number of interacting sites was found to be $\sim 1$ (Hill coefficient $n=1$ ) suggesting that only a single class of binding sites was involved and non-cooperative binding phenomena obeying the neighbour exclusion principle ruled the bis-Azo-DNA interaction.

\section{Determination of the binding mechanism by displacement assay}

No luminescence was observed for bis-Azo-2N and bis-Azo-3N upon excitation either in aqueous solution or in the presence of DNA at the concentrations used. Therefore, a displacement assay was performed using Ethidium bromide (EtBr), an archetypical intercalator, to characterize the Azo-DNA binding mode. ${ }^{13}$ If the azobenzene derivatives compete for the same DNA binding sites as $\mathrm{EtBr}$, a decrease of the fluorescence intensity of the latter would be observed. As shown in Fig. 3, the fluorescence of the EtBr-DNA complex is efficiently reduced until stoichiometry is reached.

Additional quantitative information on the fluorescence quenching data was provided by using the Stern-Volmer equation: ${ }^{14}$

$$
\frac{F_{0}}{F}=1+K_{\mathrm{q}} \tau_{0}[\mathrm{Q}]=1+K_{\mathrm{sv}}[\mathrm{Q}]
$$

where $F_{0}$ and $F$ denote the steady-state fluorescence intensities in the absence and in the presence of the quencher (azobenzene derivatives), respectively. $K_{\mathrm{sv}}$ is the Stern-Volmer quenching rate constant, [Q] is the azo concentration, $K_{\mathrm{q}}$ is the apparent quenching rate constant of the biomolecules which reflects the efficiency of quenching or in other words the accessibility of the 


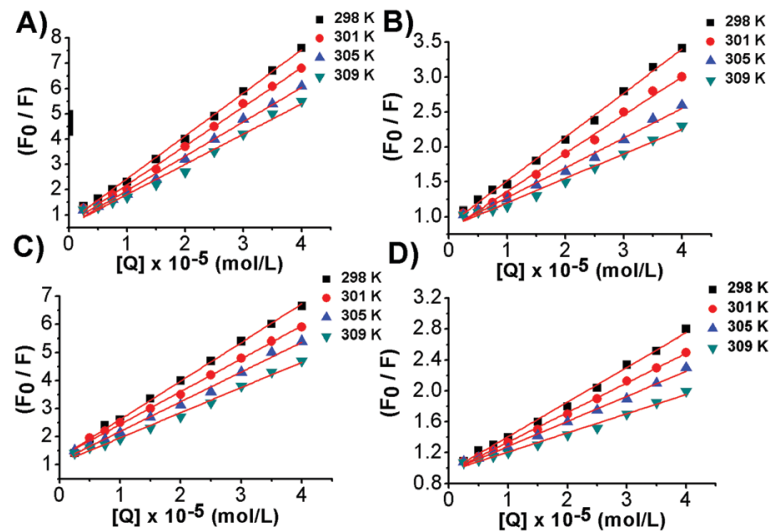

Fig. 4 Stern-Volmer plots for the fluorescence quenching of the $\mathrm{EtBr}$ DNA system by (A) bis-Azo-3N trans, (B) bis-Azo-2N trans, (C) bis-Azo-3N cis and (D) bis-Azo-2N cis at 298, 301, 305 and 309 K. $F_{0}$ and $F$ are the fluorescence intensity values of the $\mathrm{EtBr}$-DNA complex in the absence as well as in the presence of different concentrations of photochromic molecules, respectively.

fluorophore to the quencher and its absolute value can be calculated using the Smoluchowski equation (for further background reading the interested reader is referred to Lakowicz's book referenced as 14 in the current manuscript) and $\tau_{0}$ is the average excited-state lifetime of biomolecules without a quencher taken as $10^{-8} \mathrm{s.}^{14}$

From the plot of eqn (4) (Fig. 4), the values of $K_{\mathrm{sv}}$ and $K_{\mathrm{q}}$ were obtained at different temperatures and listed in Table 2.

The simple linear behaviour observed in the curves suggested a single component donor quenching system that would be expected for one major binding mode in good agreement with the findings from the UV-Vis data.

It is well known that fluorescence quenching can be static, resulting from the formation of a fluorophore-quencher complex or dynamic usually ascribed to a diffusive encounter between the fluorophore and the quencher. ${ }^{14}$ Static and dynamic quenching can be distinguished by their different dependencies on temperature. Higher temperatures lead to a larger amount of collisional quenching, while static quenching typically results in the dissociation of weakly bound complexes. ${ }^{14}$ The $K_{\mathrm{sv}}$ temperature-dependence analysis shows that less quenching occurs at higher temperatures strongly suggesting that the formation of azobenzene-DNA complexes follows a static mechanism. Further evidence was provided by the analysis of $K_{\mathrm{q}}$ values. Diffusion-controlled quenching typically shows average $K_{\mathrm{q}}$ values $\approx 10^{10} \mathrm{M}^{-1} \mathrm{~s}^{-1}$. For instance, the quenching of tryptophan by acrylamide or oxygen is found to be 1.2 and $0.59 \times 10^{10} \mathrm{M}^{-1} \mathrm{~s}^{-1}$, respectively, due to collisional quenching. ${ }^{14}$ Our systems showed $K_{\mathrm{q}}$ values much higher than the maximum diffusion collisional quenching rate of various quenchers with biopolymers $\approx 2.0 \times 10^{10} \mathrm{M}^{-1} \mathrm{~s}^{-1}$, therefore confirming the static nature of the process and the involvement of specific interactions between the molecular photoswitches and the biopolymer.

Static complex formation can be further confirmed by the modification of the absorption spectra due to stacking interactions arising from the insertion of the azobenzene moiety among the duplex base pairs (vide supra), thus ruling out any fluorescence quenching process through dynamic collisions.

\section{Fluorescence binding data analysis}

By exploiting the fluorescence titration data and assuming static quenching the association constant $\left(K_{\mathrm{f}}\right)$ and the number of excluded binding sites $(n)$ were analysed according to the following equation: ${ }^{15}$

$$
\log \frac{\left[\left(F_{0}-F\right)\right]}{F}=\log K_{\mathrm{f}}+n \log [Q]
$$

The plots of $\log \left[\left(F_{0}-F\right) / F\right]$ versus $\log [\mathrm{Q}]$ were linear (Fig. 5) and the values of $K_{\mathrm{f}}$ and $n$, shown in Table 3, were calculated at four different temperatures.

The values of apparent association constants and the number of binding sites obtained by a fluorescence displacement assay show a strong and specific binding affinity of the photochromes for double-stranded DNA. The magnitudes of these values, as expected, were higher for the stable trans isomer than for the metastable cis conformer, in good agreement with the UV-Vis data. Interestingly, the $K_{\mathrm{f}}$ and $n$ temperature trend was found to be different for the two isomers. The decrease of these values, observed for the cis isomers, was in accordance with the $K_{\mathrm{sv}}$ 's temperature dependence due to the reduction of the stability of

Table 2 Stern-Volmer $\left(K_{\mathrm{sv}}\right)$ and quenching rate constant $\left(K_{\mathrm{q}}\right)$ of the interaction between the photochromes and DNA at various temperatures

\begin{tabular}{|c|c|c|c|c|}
\hline \multirow[b]{2}{*}{$T(\mathrm{~K})$} & \multicolumn{2}{|l|}{ bis-Azo-2N trans } & \multicolumn{2}{|l|}{ bis-Azo-2N cis } \\
\hline & $K_{\mathrm{sv}} \mathrm{M}^{-1}$ & $K_{\mathrm{q}} \mathrm{M}^{-1} \mathrm{~s}^{-1}$ & $K_{\mathrm{sv}} \mathrm{M}^{-1}$ & $K_{\mathrm{q}} \mathrm{M}^{-1} \mathrm{~s}^{-1}$ \\
\hline 298 & $6.3 \pm 0.2 \times 10^{4}$ & $6.3 \pm 0.2 \times 10^{12}$ & $4.5 \pm 0.1 \times 10^{4}$ & $4.5 \pm 0.1 \times 10^{12}$ \\
\hline 301 & $5.5 \pm 0.4 \times 10^{4}$ & $5.5 \pm 0.4 \times 10^{12}$ & $3.8 \pm 0.3 \times 10^{4}$ & $3.8 \pm 0.3 \times 10^{12}$ \\
\hline 305 & $4.3 \pm 0.2 \times 10^{4}$ & $4.3 \pm 0.2 \times 10^{12}$ & $3.2 \pm 0.2 \times 10^{4}$ & $3.2 \pm 0.2 \times 10^{12}$ \\
\hline \multirow[t]{2}{*}{309} & $3.5 \pm 0.3 \times 10^{4}$ & $3.5 \pm 0.3 \times 10^{12}$ & $2.5 \pm 0.3 \times 10^{4}$ & $2.5 \pm 0.3 \times 10^{12}$ \\
\hline & \multicolumn{2}{|l|}{ bis-Azo-3N trans } & \multicolumn{2}{|l|}{ bis-Azo-3N cis } \\
\hline$T(\mathrm{~K})$ & $K_{\mathrm{sv}} \mathrm{M}^{-1}$ & $K_{\mathrm{q}} \mathrm{M}^{-1} \mathrm{~s}^{-1}$ & $K_{\mathrm{sv}} \mathrm{M}^{-1}$ & $K_{\mathrm{q}} \mathrm{M}^{-1} \mathrm{~s}^{-1}$ \\
\hline 298 & $1.7 \pm 0.3 \times 10^{5}$ & $1.7 \pm 0.3 \times 10^{13}$ & $1.4 \pm 0.1 \times 10^{5}$ & $1.4 \pm 0.1 \times 10^{13}$ \\
\hline 301 & $1.5 \pm 0.2 \times 10^{5}$ & $1.5 \pm 0.2 \times 10^{13}$ & $1.2 \pm 0.1 \times 10^{5}$ & $1.2 \pm 0.1 \times 10^{13}$ \\
\hline 305 & $1.4 \pm 0.3 \times 10^{5}$ & $1.4 \pm 0.3 \times 10^{13}$ & $1.1 \pm 0.3 \times 10^{5}$ & $1.1 \pm 0.3 \times 10^{13}$ \\
\hline 309 & $1.2 \pm 0.2 \times 10^{5}$ & $1.2 \pm 0.2 \times 10^{13}$ & $9.0 \pm 0.2 \times 10^{4}$ & $9.0 \pm 0.2 \times 10^{12}$ \\
\hline
\end{tabular}



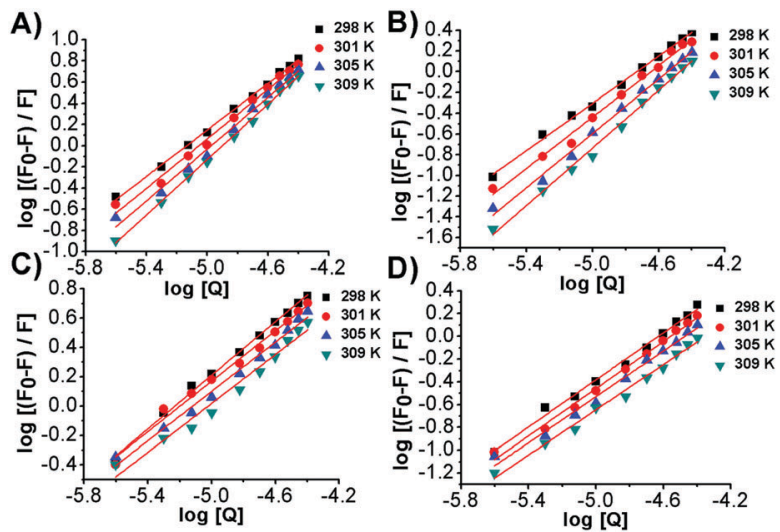

Fig. 5 Plots of $\log \left(F_{0}-F\right) / F$ versus (A) $\log [$ bis-Azo-3N trans], (B) $\log [$ [bisAzo-2N trans], (C) log[bis-Azo-3N cis] and (D) log[bis-Azo-2N cis] at 298 , 301,305 and 309 K. $F_{0}$ and $F$ are the fluorescence intensity values of the $\mathrm{EtBr}$-DNA complex in the absence as well as in the presence of different concentrations of photochromic molecules, respectively.

Table 3 Association constants $\left(K_{\mathrm{f}}\right)$ and the number of excluded binding sites $(n)$ for the interaction between the photochromes and DNA at various temperatures

\begin{tabular}{llllll}
\hline & bis-Azo-2N trans & & & bis-Azo-2N cis & \\
\cline { 2 - 3 } \cline { 5 - 6 }$T(\mathrm{~K})$ & $K_{\mathrm{f}} \mathbf{M}^{-1}$ & $n$ & & $K_{\mathrm{f}} \mathbf{M}^{-1}$ & $n$ \\
\hline 298 & $2.4 \pm 0.2 \times 10^{5}$ & 1.1 & & $6.1 \pm 0.3 \times 10^{4}$ & 1.0 \\
301 & $5.7 \pm 0.1 \times 10^{5}$ & 1.2 & & $5.2 \pm 0.2 \times 10^{4}$ & 1.0 \\
305 & $9.1 \pm 0.4 \times 10^{5}$ & 1.3 & & $3.1 \pm 0.3 \times 10^{4}$ & 1.0 \\
309 & $1.7 \pm 0.3 \times 10^{6}$ & 1.4 & & $2.1 \pm 0.4 \times 10^{4}$ & 1.0 \\
\hline & bis-Azo-3N trans & & & bis-Azo-3N cis & \\
$T(\mathrm{~K})$ & $K_{\mathrm{f}} \mathbf{M}^{-1}$ & $n$ & & $K_{\mathrm{f}} \mathbf{M}^{-1}$ & $n$ \\
\hline 298 & $4.3 \pm 0.2 \times 10^{5}$ & 1.1 & & $6.0 \pm 0.2 \times 10^{4}$ & 0.9 \\
301 & $7.9 \pm 0.1 \times 10^{5}$ & 1.2 & & $2.9 \pm 0.3 \times 10^{4}$ & 0.9 \\
305 & $1.2 \pm 0.3 \times 10^{6}$ & 1.2 & & $2.0 \pm 0.4 \times 10^{4}$ & 0.9 \\
309 & $2.6 \pm 0.2 \times 10^{6}$ & 1.3 & & $1.5 \pm 0.2 \times 10^{4}$ & 0.8 \\
\hline
\end{tabular}

the azobenzene-DNA complexes. It is well known that an increase in temperature can enhance the thermal stability of the planar trans form, which may be responsible for the increase in the magnitude of the association constants. The apparent unitary values calculated in the fluorescent intercalator displacement assay (FID) suggested that one molecule of Et-Br was displaced upon binding of one molecule of photochrome in good agreement with the size of the binding site discussed below.

\section{Elucidation of the binding parameters}

The binding site size of the azobenzene derivatives to ds-DNA, in both conformations, was evaluated based on luminescence titration using the mole ratio method, keeping constant the concentration of EtBr and DNA and changing that of the photochromes. Plots of variations in fluorescence intensity at $590 \mathrm{~nm} v s$. the Azobenzene/DNA mole ratio are shown in Fig. 6 . From the inflection point the molar ratios Azobenzene/DNA were found to be $\approx 0.4$, and the number of base pairs involved in the association process are listed in Table 4.

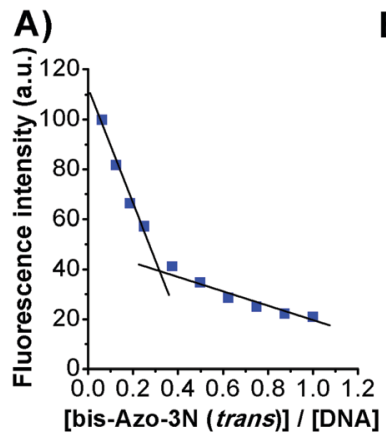

B)

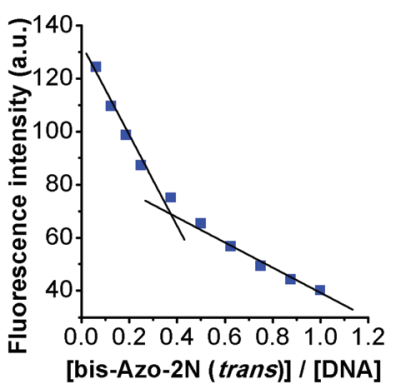

Fig. 6 Plots of (A) bis-Azo-3N(trans)-DNA and (B) bis-Azo-2N(trans)DNA fluorescence intensity versus the mole ratio.

Table 4 Binding size for the photochrome-DNA complexes

\begin{tabular}{llll}
\hline $\begin{array}{l}\text { bis-Azo-2N } \\
\text { trans/DNA (bp) }\end{array}$ & $\begin{array}{l}\text { bis-Azo-2N } \\
\text { cis/DNA (bp) }\end{array}$ & $\begin{array}{l}\text { bis-Azo-3N } \\
\text { trans/DNA (bp) }\end{array}$ & $\begin{array}{l}\text { bis-Azo-3N } \\
\text { cis/DNA (bp) }\end{array}$ \\
\hline 2.56 & 2.38 & 2.94 & 2.63
\end{tabular}

The size of the binding sites of the azobenzene derivatives agrees with those found for classical intercalators in accordance with the neighbour exclusion principle. ${ }^{16}$ The number of base pairs involved in the association process seems to be also related to the size of the photochromes and to their spatial configuration. Moreover, from the slope of the binding isotherm, the DNA binding affinity of the azobenzene derivatives followed the order bis-Azo-3N trans $>$ bis-Azo-2N trans $>$ bis-Azo-3N cis $>$ bis-Azo-2N cis (data shown only for bis-Azo-3N trans and bis-Azo-2N trans). These findings are in accordance with the results found using various spectroscopic approaches.

\section{Thermodynamic studies}

Thermodynamic parameters, such as the entropic and enthalpic contributions to the whole binding process, are good indicators of the type of interaction that regulates such macromolecular interactions. Positive values of both enthalpy and entropy can be ascribed mainly to short-range interactions and dehydration effects, whereas negative enthalpy and positive entropy values indicate mainly longrange interactions of ionic nature. ${ }^{17}$ If the enthalpy change $\left(\Delta H^{0}\right)$ does not vary significantly in the temperature range studied, the thermodynamic parameters, listed in Table 6 , using the $K_{\mathrm{a}}$ values determined at four different temperatures listed in Table 5 , can be evaluated by applying the Van't Hoff equation: ${ }^{18}$

$$
\begin{gathered}
\log K_{\mathrm{a}}=-\frac{\Delta H^{0}}{2.303 R T}+\frac{\Delta S^{0}}{2.303 R}=-\frac{\Delta G^{0}}{2.303 R T} \\
-R T \ln \left(K_{\mathrm{a}}\right)=\Delta G=\Delta H^{0}-T \Delta S^{0}
\end{gathered}
$$

The values of $\Delta H^{0}$ and $\Delta S^{0}$ were determined from the slope and the intercept of the linear plot between $\log K_{\mathrm{a}}$ and the reciprocal absolute temperature (ESI, $\dagger$ Fig. S2A-D).

The negative values of $\Delta G^{0}$ clearly indicate the spontaneity of the process. A different trend of the thermodynamic parameters $\left(\Delta H^{0}\right.$ and $\left.\Delta S^{0}\right)$ was observed for the two conformers. 
Table 5 Values of the intrinsic binding constant $\left(K_{\mathrm{a}}\right)$ for the photochrome-DNA systems calculated at different temperatures $298,301,305$ and $309 \mathrm{~K}$ by using eqn (1)

\begin{tabular}{|c|c|c|c|c|}
\hline & bis-Azo-2N trans & bis-Azo-2N $c i s$ & bis-Azo-3N trans & bis-Azo-3N cis \\
\hline 298 & $5.3 \pm 0.3 \times 10^{4}$ & $2.6 \pm 0.2 \times 10^{4}$ & $7.1 \pm 0.4 \times 10^{4}$ & $5.1 \pm 0.4 \times 10^{4}$ \\
\hline 305 & $6.5 \pm 0.2 \times 10^{4}$ & $2.1 \pm 0.4 \times 10^{4}$ & $8.5 \pm 0.3 \times 10^{4}$ & $4.0 \pm 0.1 \times 10^{4}$ \\
\hline 309 & $7.2 \pm 0.5 \times 10^{4}$ & $1.9 \pm 0.2 \times 10^{4}$ & $9.5 \pm 0.3 \times 10^{4}$ & $3.5 \pm 0.3 \times 10^{4}$ \\
\hline
\end{tabular}

The negative enthalpy $\left(\Delta H^{0}\right)$ and the positive entropy $\left(\Delta S^{0}\right)$ found for the metastable cis conformation indicate that complex formation is driven and stabilized mainly by long-range forces including electrostatic, hydrogen bonding and van der Waals interactions. The positive value of both enthalpy and entropy observed for the stable trans isomers suggests that the free-energy contribution to adduct stabilization arises mainly by short-range contacts of a hydrophobic character even though long-range interactions cannot be excluded. The substantial difference, for the trans and cis isomers, in stabilizing the DNA adduct seems to be related to conformational changes of the photochromes occurring upon light irradiation. The reduced free volume of the planar trans form allows the azobenzene core an easy transition among the non-polar DNA bases resulting in favourable hydrophobic contacts, whereas the larger molecular size of the bent, nonplanar cis form displaces to some degree the ligand from the stacked position, allowing an additional surface binding with the functional groups positioned on the edge of DNA bases and/or with the phosphate backbone of the duplex.

Since the thermodynamic studies show positive values of entropy for all the photochrome-DNA adducts the binding may entail the release of bound ions and therefore additional ionic strength investigations were carried out and are presented below.

\section{Fourier transform infrared (FT-IR) spectroscopy}

Azobenzene-DNA FT-IR spectra, recorded for solutions with different DNA/azobenzene molar ratios, are characterized by shifts in wavenumber and variations in intensity relative to the symmetric and asymmetric vibration of phosphate groups and of those related to the DNA bases (ESI, $\dagger$ Fig. S3, S4A-D and S5A-D).

\section{Interaction with nitrogenous bases}

Evidence for azobenzene-base binding comes from the spectral and intensity changes observed upon ligand-DNA complexation. In particular, in the system with a low DNA/bis-Azo-2N(trans) mole ratio $(1 / 20,1 / 10$ and $1 / 6.6)$ the bands assigned to the bases at $1701 \mathrm{~cm}^{-1}$ (G), $1527 \mathrm{~cm}^{-1}$ (C) and $1488 \mathrm{~cm}^{-1}$ (C) were shifted to 1687,1529 and $1486 \mathrm{~cm}^{-1}$, respectively, while the bands at $1652(\mathrm{~T})$ and $1417(\mathrm{G}) \mathrm{cm}^{-1}$ were not perturbed. When the molar ratios of bis-Azo-2N(trans) to DNA increased ( $r=1 / 5$ and $r=1 / 4)$, the bands at 1701,1527 and $1488 \mathrm{~cm}^{-1}$ were further shifted to 1683,1532 and $1485 \mathrm{~cm}^{-1}$ in conjunction with the bands at 1652 (T) and 1417 (G) $\mathrm{cm}^{-1}$ shifted to 1656 and $1419 \mathrm{~cm}^{-1}$, respectively. Similarly, the bis-Azo-3N(trans)-DNA system at a low mole ratio is characterized by the shifting of the bands at 1701 and $1417 \mathrm{~cm}^{-1}$ to 1681 and $1419 \mathrm{~cm}^{-1}$, respectively, with no perturbation of the other bands related to the nitrogenous DNA bases. At higher molar ratios, the bands at 1701 and $1417 \mathrm{~cm}^{-1}$ were not further perturbed, while the bands at 1652, $1527,1488 \mathrm{~cm}^{-1}$ were shifted to 1656,1533 and $1483 \mathrm{~cm}^{-1}$, respectively. All the shifts of the DNA bases are also associated with changes in their relative intensity (ESI, $\dagger$ Fig. S5A-D). It is important to stress that no shift was observed for the bands at 1606, 1579, 1294, 1068, and $962 \mathrm{~cm}^{-1}$ for each DNA/ azobenzene(trans) molar ratio considered, thus ruling out their involvement in the DNA interaction.

Similarly, the azobenzene derivatives in cis conformation act as their trans isomers, however, with some remarkable differences. In particular, in the system with a low DNA/ bis-Azo-2N(cis) mole ratio $(1 / 20,1 / 10$ and $1 / 6.6)$ the bands related to the bases at $1701 \mathrm{~cm}^{-1}$ (G), $1652 \mathrm{~cm}^{-1}$ (T), $1527 \mathrm{~cm}^{-1}$ (C), $1488 \mathrm{~cm}^{-1}$ (C) and $1417 \mathrm{~cm}^{-1}$ (G) were shifted to 1684,1648 , 1531, 1484 and $1419 \mathrm{~cm}^{-1}$, respectively. By increasing the concentration of the ligand $(r=1 / 5$ and $r=1 / 4)$ no additional shift of the bands at 1701,1652 and $1488 \mathrm{~cm}^{-1}$ was noticed while the bands at 1527 and $1417 \mathrm{~cm}^{-1}$ were further upward shifted to 1534 and $1420 \mathrm{~cm}^{-1}$, respectively. Similar shifts of these bands were also found for the bis-Azo-3N(cis)-DNA systems. It is noteworthy that, unlike the trans isomers, the bent cis conformers induced also shifts of the bands at 1606 and $1579 \mathrm{~cm}^{-1}$. The spectral changes observed for such bands are indicative of a possible binding of the cis-photochromes either to N7 guanine and adenine reactive sites or $\mathrm{O} 6$ on guanine atoms as well as to adjacent adenine and guanine N3 residues located in the DNA grooves. As expected, the interaction of the azobenzene derivatives in the cis form seems to involve the same binding sites as the trans isomer, with additional surface contacts through the edge of DNA in agreement with the thermodynamic analysis.

\section{Interaction with phosphate-sugar backbone}

At a low DNA/bis-Azo-2N(trans) mole ratio, the bands related to asymmetric and symmetric stretching vibration of the phosphate groups at 1370, 1242, 1093 and $730 \mathrm{~cm}^{-1}$ were shifted to 1366, 1238, 1085 and $725 \mathrm{~cm}^{-1}$, respectively. The same bands related to the DNA/bis-Azo-3N(trans) systems were shifted to 1373, 1237, 1085 and $725 \mathrm{~cm}^{-1}$, respectively. At higher molar ratios for the former system, the bands at 1370 and $1093 \mathrm{~cm}^{-1}$ were shifted to 1364 and $1084 \mathrm{~cm}^{-1}$, respectively, and no further shift of the bands at 1242 and $730 \mathrm{~cm}^{-1}$ was observed. At high DNA/bis-Azo-3N(trans) mole ratio systems, the bands at 1370, 1242 and $1093 \mathrm{~cm}^{-1}$ were further shifted to 1374, 1235 and $1080 \mathrm{~cm}^{-1}$, respectively, and no additional perturbation of the 
Table 6 Thermodynamic parameters of the interaction between the azobenzene derivatives and DNA

\begin{tabular}{|c|c|c|c|c|c|c|}
\hline \multirow[b]{2}{*}{$T(\mathrm{~K})$} & \multicolumn{3}{|l|}{ bis-Azo-2N trans } & \multicolumn{3}{|l|}{ bis-Azo-2N cis } \\
\hline & $\Delta H^{0}\left(\mathrm{~kJ} \mathrm{~mol}^{-1}\right)$ & $\Delta S^{0}\left(\mathrm{~J} \mathrm{~mol}^{-1} \mathrm{~K}^{-1}\right)$ & $\Delta G^{0}\left(\mathrm{~kJ} \mathrm{~mol}^{-1}\right)$ & $\Delta H^{0}\left(\mathrm{~kJ} \mathrm{~mol}^{-1}\right)$ & $\Delta S^{0}\left(\mathrm{~J} \mathrm{~mol}^{-1} \mathrm{~K}^{-1}\right)$ & $\Delta G^{0}\left(\mathrm{~kJ} \mathrm{~mol}^{-1}\right)$ \\
\hline $\begin{array}{l}298 \\
301 \\
305 \\
309\end{array}$ & $22.9 \pm 3.1$ & $167.3 \pm 11.2$ & $\begin{array}{l}-27.0 \pm 0.2 \\
-27.4 \pm 0.2 \\
-28.1 \pm 0.1 \\
-28.7 \pm 0.3\end{array}$ & $-21.5 \pm 2.7$ & $12.4 \pm 2.4$ & $\begin{array}{l}-25.2 \pm 0.1 \\
-25.2 \pm 0.1 \\
-25.2 \pm 0.2 \\
-25.3 \pm 0.1\end{array}$ \\
\hline $\begin{array}{l}298 \\
301 \\
305 \\
309\end{array}$ & $20.5 \pm 5.2$ & $161.5 \pm 17.3$ & $\begin{array}{l}-27.7 \pm 0.2 \\
-28.2 \pm 0.1 \\
-28.8 \pm 0.2 \\
-29.4 \pm 0.2\end{array}$ & $-23.7 \pm 4.5$ & $10.0 \pm 3.1$ & $\begin{array}{l}-26.7 \pm 0.2 \\
-26.7 \pm 0.2 \\
-26.8 \pm 0.1 \\
-26.8 \pm 0.2\end{array}$ \\
\hline
\end{tabular}

band at $730 \mathrm{~cm}^{-1}$ was detected. The shifting of the $\mathrm{PO}_{2}$ bands observed for the azobenzene( $c i s$-DNA systems were found to be similar to those reported above for the trans isomers and no or weak shifts of the bands at 1294, 962 and $781 \mathrm{~cm}^{-1}$ were detected for each DNA/Azobenzene molar ratio considered. The spectral changes observed may be due to the occurrence of external binding interactions probably of ionic nature between the positive multi-charged ligands and the negative duplex backbone. The insertion of the ligand among the base pairs can also destabilize the B-DNA form to some degree, therefore leading to distortion and perturbation of the sugar-phosphate backbone, which can be an additional explanation for the shifting of those bands.

Nevertheless, it is interesting that the major perturbation of the deoxyribose sugar vibration band at $1068 \mathrm{~cm}^{-1}$, arising upon interaction with the non-planar cis conformer, provides direct evidence of a possible stronger outside binding contribution with the sugar-phosphate backbone of the DNA double helix than with respect to the planar isomer, which can instead face the hydrophobic cavity of the duplex.

\section{Changeover in the duplex DNA conformation}

The B-DNA marker bands, for both the azobenzene derivatives in trans conformation, at $833 \mathrm{~cm}^{-1}$ attributed to $\mathrm{S}_{-} \mathrm{C}_{2}$ endo/anti sugar pucker-phosphodiester mode and that at $889 \mathrm{~cm}^{-1}$ assigned to sugar phosphate-stretch, ${ }^{5 d}$ were overall shifted upward and downward to 839 and $881 \mathrm{~cm}^{-1}$, respectively. Moreover, the band at $1456 \mathrm{~cm}^{-1}$ assigned to a $\mathrm{C}-\mathrm{N}$ glycosyl bond, also responsible for the B-DNA form, ${ }^{19}$ was overall shifted downward to $1445 \mathrm{~cm}^{-1}$. The DNA-azobenzene(cis) systems were also characterized by the perturbation of the DNA marker bands at 833 and $889 \mathrm{~cm}^{-1}$ but unlike the trans derivative, the cis isomer weakly perturbs the band at $1456 \mathrm{~cm}^{-1}$ at all the molar ratios considered. Those results indicated that even if the bent non-planar cis form affected the DNA secondary structure the B-DNA conformational transition is less likely to occur, compared to the elongated planar trans form. These findings are in accordance with the CD spectroscopic results discussed below.

\section{Circular dichroism spectral studies}

In order to better assess and understand the ability of the photochromes to induce conformational changes in the DNA secondary structure, circular dichroism (CD) spectra were studied (Fig. 7 and ESI, $\dagger$ Fig. S6). The canonical B-DNA form is characterized by four major characteristic $\mathrm{CD}$ bands: $211 \mathrm{~nm}$ (negative), $224 \mathrm{~nm}$ (positive), $245 \mathrm{~nm}$ (negative) and $275 \mathrm{~nm}$ (positive). ${ }^{20}$ The azobenzene derivatives being the object of the present study do not possess a chiral centre and thus they are CD inactive. However, upon association with DNA, a bisignate induced circular dichroic band (ICD) appears for both their isomeric forms. The appearance of ICD signals in the region between 310 and $540 \mathrm{~nm}$ can be attributed to degenerate coupling of the electric transition moment of the azobenzene derivatives with those of the chirally arranged DNA base pairs. It is important to stress that excitonic coupling of the azobenzene chromophores may be excluded since the ICD magnitude is linear with respect to the concentration of bound molecules. ${ }^{21}$ Intercalators usually display a weak negative or bisignate ICD signal, as found for some anthracene-spermine derivatives and for the mono-substituted photosensitive polyamine Azo-3N, whereas larger positive ICD
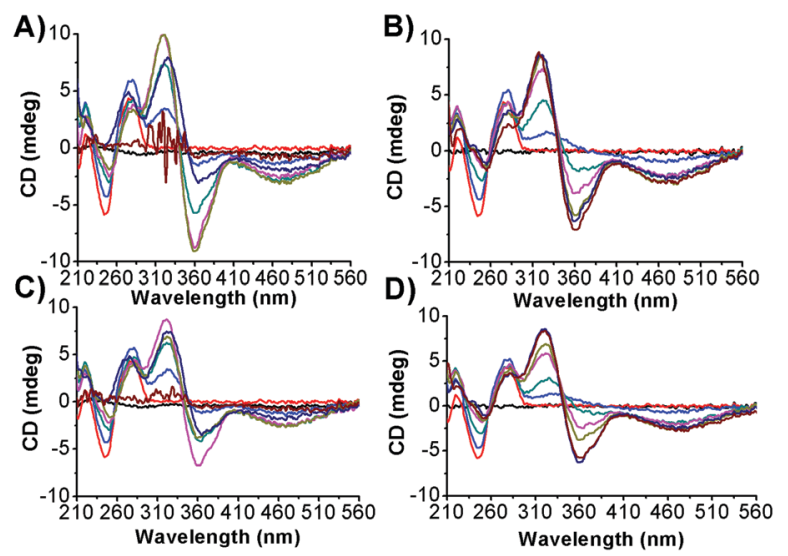

Fig. 7 Circular dichroism spectra of ds-DNA (red line) at different azobenzene/DNA molar ratios ( $r$ ). $r=5$ (blue line), $r=1.66$ (green line), $r=1$ (pink line), $r=0.71$ (yellow line), $r=0.55$ (violet line) and $r=0.42$ (brown line). The optical inactivity of the photochromes is shown by the black line. (A) bis-Azo-3N trans-DNA system, (B) bis-Azo-2N trans-DNA system, (C) bis-Azo-3N cis-DNA system and (D) bis-Azo-2N cis-DNA system. 
Table 7 Apparent association constant $\left(K_{\mathrm{a}}\right)$ of binding of the azobenzene derivatives to DNA at various salt concentrations calculated by using eqn (1). $Z \Psi$ is the slope of the dependence $\log K_{a} v s$. $\log [\mathrm{NaCl}]$ for each azobenzene-DNA system considered

\begin{tabular}{lllll}
\hline & bis-Azo-2N trans & bis-Azo-2N cis & \multicolumn{1}{l}{ bis-Azo-3N trans } \\
$K_{\mathrm{a}}\left(\mathrm{M}^{-1}\right)$ & \multicolumn{1}{c}{$\begin{array}{l}\text { bis-Azo-3N cis } \\
K_{\mathrm{a}}\left(\mathrm{M}^{-1}\right)\end{array}$} \\
\hline 2.5 & $K_{\mathrm{a}}\left(\mathrm{M}^{-1}\right)$ & $K_{\mathrm{a}}\left(\mathrm{M}^{-1}\right)$ & $6.3 \pm 0.3 \times 10^{4}$ & $3.2 \pm 0.4 \times 10^{4}$ \\
10 & $5.0 \pm 0.3 \times 10^{4}$ & $1.4 \pm 0.2 \times 10^{4}$ & $2.0 \pm 0.1 \times 10^{4}$ & $1.4 \pm 0.2 \times 10^{4}$ \\
20 & $1.0 \pm 0.3 \times 10^{4}$ & $3.2 \pm 0.4 \times 10^{3}$ & $1.3 \pm 0.4 \times 10^{4}$ & \\
50 & $4.0 \pm 0.2 \times 10^{3}$ & $2.0 \pm 0.2 \times 10^{3}$ & $5.0 \pm 0.4 \times 10^{3}$ & \\
$Z \Psi$ & $1.6 \pm 0.3 \times 10^{3}$ & $1.0 \pm 0.2 \times 10^{3}$ & 2.6 & 3.1
\end{tabular}

signals are attributable to the groove-binding geometry. ${ }^{7 e, 20 b, 21,22}$ It turns out that the changes observed can be ascribed to the ability of the photochromes to intercalate the nucleobases, even if this behaviour seems to be smaller for the hydrophilic cis form than for the hydrophobic trans conformer. In order to better elucidate the association mechanism, the intrinsic positive and negative B-DNA bands were analysed. ${ }^{17}$ At a low DNA/azobenzene mole ratio $(r=5)$, an increase in ellipticity of the bands at 275, 224 and $211 \mathrm{~nm}$ along with a decrease (shifting towards zero) of the CD band at $245 \mathrm{~nm}$ was observed upon interaction of the photochromes in both their conformations. The presence of isodichroic points in the CD spectra is indicative of a perturbation of the duplex secondary structure providing evidence for the formation of the fast, two state and highly cooperative partial B-to-A DNA transition. ${ }^{23}$ Upon increasing the concentration of bis-Azo-2N $(r=1.66 ; r=1 ; r=0.71 ; r=0.55$ and $r=0.42)$ and bis-Azo-3N $(r=1.66 ; r=1$ and $r=0.71)$ in both their isomeric forms, a similar trend of the intrinsic DNA CD band changes was noted. The bands at 275 and $245 \mathrm{~nm}$ gradually decreased with increasing ligand concentration and an overall red shift of the negative band of $12 \mathrm{~nm}$ was observed. Moreover, both the bands at 224 and $211 \mathrm{~nm}$ show an overall decrease of intensity at high DNA/bis-Azo-2N ratios $(r=0.55$ and $r=0.42)$ and at a medium DNA/bis-Azo-3N ratio $(r=1$ and $r=0.71)$. CD changes here can be ascribed to the slow A-to-Z DNA transition, which is in good agreement with polyamine induced interconversion: B-DNA, A-DNA and Z-DNA. ${ }^{23,24}$ Interestingly, progressive addition of bis-Azo-3N in both conformations $(r=0.55)$ resulted in a decrease of the intensity of the positive B-to-A DNA band at $275 \mathrm{~nm}$ which may be ascribed to the formation of the condensed multi molecular $\Psi$-DNA form. ${ }^{25}$ Further ligand addition $(r=0.42)$ gave rise to a complete DNA precipitation. It should be noted that at equal amounts of ligand bound to the duplex the ability of the ligands to induce DNA conformational changes grows on increasing the number of methylene spacers and positive charges at the nitrogens (bis-Azo-3N $>$ bis-Azo-2N) which is consistent with our spectroscopic results discussed above. These findings unambiguously differ from those reported for the mono-substituted Azo-3N(trans) in which a monotonic trend of changes occurring on the DNA chirality was observed. $^{7 e}$ We speculate that the number of charges distributed along the photosensitive polyamines are not only deeply responsible for the changes occurring on the duplex morphology but they also exert a pivotal role in conferring reversibility to the process once the photochrome is bound to the biopolymer (Table 7).
Effects of varying concentrations of a monovalent salt on the affinity of azobenzene derivatives for ds-DNA

Analysis of the effect of changes in salt concentration on the equilibrium binding constant, $K_{\mathrm{a}}$, for the azobenzene-DNA complexes was carried out according to the theory of Record et $a l .{ }^{26}$ In the presence of a monovalent salt MX, the number of ionic interactions and counterions released involved in a ligand-nucleic acid adduct can be estimated by measuring the derivative $\delta \log \left(K_{\mathrm{a}}\right) / \delta \log \left[\mathrm{M}^{+}\right]$. In a sufficiently diluted solution of the monovalent salt, the predicted quantitative dependence of the association constant on the ionic strength is: ${ }^{27}$

$$
\frac{\delta \log K_{\mathrm{a}}}{\delta \log \left[\mathrm{M}^{+}\right]}=-Z \Psi
$$

where $\Psi$ is a constant ( 0.88 for B-DNA form) and the linear plot of $\log K_{\mathrm{a}}$ on $\log \left[\mathrm{M}^{+}\right]$allows to determine $Z .^{25 a}$

The least squares slopes (ESI, $\dagger$ Fig. S7A-D) were 1.7, 1.8, 2.6 and 3.1 for the bis-Azo-2N and bis-Azo-3N in trans and cis form, respectively, implying that $\sim 2$ and $\sim 3$ ions are released in the interaction of each monomer of the photochrome with the biopolymer in the salt range studied. Consequently the number of phosphate groups on the DNA involved in the ionic interactions with the positive charged ligands were $\sim 2$ and $\sim 3$ for bis-Azo-2N and bis-Azo-3N, respectively, which is in good agreement with the intrinsic positive charges of azo compounds (ESI $\dagger$ p. S12). The slightly higher number of ions released and consequently neutralized phosphates found for the cis isomers further confirm the prediction that the bent non-planar form is hindered to fit entirely the intercalation site resulting in an end-stacking mode with the substituent arms more faced to the external edges of the duplex. The overall net positive charge distribution along the azobenzene substituent groups exerts a pivotal role in photochrome-DNA stabilization and seems to be the major driving force for the resulting conformational changes occurring on the intrinsic B-DNA morphology.

\section{Conclusions}

In summary, the biophysical DNA-binding properties of two water-soluble polycationic azobenzene derivatives (bis-Azo-2N and bis-Azo-3N) have been comprehensively investigated as functions of the photochromic states and temperature, salt and DNA concentration. The qualitative and quantitative binding data analysis obtained by the various spectroscopic approaches indicates that the order of stability of the photochromes bound 
to DNA was bis-Azo-3N trans $>$ bis-Azo-2N trans $>$ bis-Azo-3N cis $>$ bis-Azo-2N cis. These results unequivocally establish that the number and magnitude of positive charges along the surface of the molecules as well as the intrinsic isomeric states have a profound effect on DNA modification. The results of the fluorescence displacement assays clearly establish the major ability of the hydrophobic planar azobenzene derivatives to displace the archetypical intercalator Ethidium bromide compared to the hydrophilic non-planar bent cis form. These findings hint at the possibility that the different hydrophobic/hydrophilic character possessed by the two conformers may be exploited during the well-known resolubilization process of DNA occurring at high polyamine concentrations since the disruption of the liquid crystalline order of the biopolymer is regulated by the ability of polyamines to enter into the hydrophobic environment of the DNA helix. Evaluation of the thermodynamic parameters, beyond confirming the spontaneity of the process, highlights that the increment of entropy in the system mainly arises from the release of monovalent counterions from the duplex backbone which is further supported by the results of the ionic strength analysis. The FT-IR results showed that both the phosphonate backbone and the functional groups located at the edges of the DNA were involved in the complexation process. The circular dichroism data clearly demonstrated that the conformational changes induced by the photochromes on the ds-DNA were indicative of B-to-A-to-Z-like partial transitions and their relative modulation could be accomplished through a concentrationdependent manner. The overall changes occurring on the intrinsic DNA chirality upon binding of the bis-substituted compounds were in sharp contrast to those observed for the mono-substituted photoswitch Azo-3N indicating that the number of positive charges along the azobenzene template play a key role in destabilizing the B-DNA morphology as well as in conferring photo-reversibility to the binding process. Nevertheless, the relative ease of production makes these new photochromic materials attractive models for future vehicle-based gene therapy applications.

\section{Acknowledgements}

We thank Dr R. Kołkowski for the help with the graphical material. Financial support from the Polish National Science Centre OPUS project [DEC-2013/09/B/ST5/03417] and a statutory activity subsidy from the Polish Ministry of Science and Higher Education for the Faculty of Chemistry of WUST are acknowledged.

\section{Notes and references}

1 C. T. Strachan and A. P. Read, Human Molecular Genetics, Wiley-Liss, New York, 1999.

2 (a) J.-L. Coll, P. Chollet, E. Brambilla, D. Desplanques, J.-P. Behr and M. Favrot, Hum. Gene Ther., 2004, 10, 1659-1666; (b) O. Boussif, M. A. Zanta and J. P. Behr, Gene Ther., 1996, 3, 1074-1080.
3 K. Manojkumar, K. T. P. Charan, A. Sivaramakrishna, P. C. Jha, V. M. Khedkar, R. Siva, G. Jayaraman and K. Vijayakrishna, Biomacromolecules, 2015, 16, 894-903.

4 (a) C. E. Thomas, A. Ehrhardt and M. A. Kay, Nat. Rev. Genet., 2003, 4, 346-358; (b) M. Ramamoorth and A. Narvekar, J. Cardiovasc. Dis. Res., 2015, 9, GE01-GE06, DOI: 10.7860/ JCDR/2015/10443.5394.

5 (a) N. S. Templeton, Gene Therapy: Therapeutic mechanisms and strategies, Dekker, New York, 2nd edn, 2004; (b) B. Pitard, O. Aguerre, M. Airivu, A. M. Lachanges, T. Boukhnikachvili, G. Byk, C. Dubertret, D. Scherman, J. F. Mayaux and J. Crouzet, Proc. Natl. Acad. Sci. U. S. A., 1997, 94, 14412-14417; (c) R. Marty, C. N. N'soukpoé-Kossi, D. M. Charbonneau, L. Kreplak and H. A. Tajmir-Riahi, Nucleic Acids Res., 2009, 37, 5197-5207; (d) R. Marty, C. N. Nsoukpoe-Kossi, D. Charbonneau, C. M. Weinert, L. Kreplak and H. A. Tajmir-Riahi, Nucleic Acids Res., 2009, 37, 749-757; (e) M. Melinkov, V. S. Sergeyev and K. Yoshikawa, J. Am. Chem. Soc., 1995, 117, 9951-9956; $(f)$ D. Matulis, I. Rouzina and V. A. Bloomfield, J. Am. Chem. Soc., 2002, 124, 7331-7342; (g) T. J. Thomas, H. A. Tajmir-Riahi and T. Thomas, Amino Acids, 2016, 48, 2423-2431.

6 (a) P. T. Wong, K. Tang, A. Coulter, S. Tang, Jr, J. R. Baker and S. K. Choi, Biomacromolecules, 2014, 15, 4134-4145; (b) M.-L. Örberg, K. Schillén and T. Nylander, Biomacromolecules, 2007, 8, 1557-1563.

7 (a) A. Diguet, N. K. Mani, M. Geoffroy, M. Sollogoub and D. Baigl, Chem. - Eur. J., 2010, 16, 11890-11896; (b) S. Rudiuk, K. Yoshikawa and D. Baigl, Soft Matter, 2011, 7, 5854-5860; (c) A. Venancio-Marques, A. Bergen, C. Rossi-Gendron, S. Rudiuk and D. Baigl, ACS Nano, 2014, 8, 3654-3663; (d) A. Diguet, M. Yanagisawa, Y.-J. Liu, E. Brun, S. Abadie, S. Rudiuk and D. Baigl, J. Am. Chem. Soc., 2012, 134, 4898-4904; (e) M. Deiana, Z. Pokladek, J. Olesiak-Banska, P. Mlynarz, M. Samoc and K. Matczyszyn, Sci. Rep., 2016, 6, 28605; (f) P. Krawczyk, A. Kaczmarek, R. Zalesny, K. Matczyszyn, W. Bartkowiak, M. Ziolkowski and P. Cysewski, J. Mol. Model., 2009, 15, 581-590; $(g)$ K. Matczyszyn, A. Chwialkowska and J. Sworakowski, Thin Solid Films, 2008, 516, 8899-8904; (h) R. Zalesny, K. Matczyszyn, A. Kaczmarek, W. Bartkowiak and P. Cysewski, J. Mol. Model., 2007, 13, 785-791; (i) K. Matczyszyn, W. Bartkowiak and J. Leszczynski, J. Mol. Struct., 2001, 565-566, 53-57.

8 (a) M. Deiana, B. Mettra, K. Matczyszyn, K. Piela, D. Pitrat, J. Olesiak-Bańska, C. Monnereau, C. Andraud and M. Samoć, Phys. Chem. Chem. Phys., 2015, 17, 30318-30327; (b) M. Deiana, K. Matczyszyn, J. Massin, J. Olesiak-Bańska, C. Andraud and M. Samoć, PLoS One, 2015, 10, e0129817.

9 H. A. Benesi and J. H. Hildebrand, J. Am. Chem. Soc., 1949, 71, 2703-2707.

10 X.-L. Li, Y.-J. Hu, H. Wang, B.-Q. Yu and H.-L. Yue, Biomacromolecules, 2012, 13, 873-880.

11 S. Nafisi, A. A. Saboury, N. Keramat, J. F. Neault and H.-A. Tajmir-Riahi, J. Mol. Struct., 2007, 827, 35-43.

12 A. A. Sabouri and A. A. Moosavimovahedi, Biochem. Educ., 1994, 22, 48-49.

13 C. K. Nisha and S. V. Manorama, Langmuir, 2004, 20, 2386-2396. 
14 J. R. Lakowicz, Principles of Fluorescence Spectroscopy, Springer, New York, 3rd edn, 2006.

15 Y. Shy, C. Guo, Y. Sun, Z. Liu, F. Xu, Y. Zhang, Z. Wen and Z. Li, Biomacromolecules, 2011, 12, 797-803.

16 (a) M. Hossain and G. S. Kumar, Mol. BioSyst., 2009, 5, 1311-1322; (b) L. D. Williams, M. Egli, Q. Gao and A. Rich, Structure \& Function, 1992, 1, 107-125.

17 P. D. Ross and S. Subramanian, Biochemistry, 1981, 20, 3096-3102.

18 N. Ibrahim, H. Ibrahim, S. Kim, J. P. Nallet and F. Nepveu, Biomacromolecules, 2010, 11, 3341-3351.

19 D. R. Whelan, K. R. Bambery, P. Heraud, M. J. Tobin, M. Diem, D. McNaughton and B. R. Wood, Nucleic Acids Res., 2011, 39, 5439-5448.

20 (a) N. Narayanaswamy, S. Das, P. K. Samanta, K. Banu, G. P. Sharma, N. Mondal, S. K. Dhar, S. K. Pati and T. Govindaraju, Nucleic Acids Res., 2015, 43, 8651-8663; (b) N. C. Garbett, P. A. Ragazzon and J. B. Chaires, Nat. Protoc., 2007, 2, 3166-3172; (c) M. Deiana, B. Mettra, K. Matczyszyn, D. Pitrat, J. Olesiak-Banska, C. Monnereau, C. Andraud and M. Samoc, Biomacromolecules, 2016, 17, 3609-3618.
21 A. Rodger, I. S. Blagbrough, G. Adlam and M. L. Carpenter, Biopolymers, 1994, 34, 1583-1593.

22 A. Rodger, S. Taylor, G. Adlam, I. S. Blagbrough and I. S. Haworth, Bioorg. Med. Chem., 1995, 3, 861-872.

23 J. Kypr, I. Kejnovska, D. Renciuk and M. Vorlıckova, Nucleic Acids Res., 2009, 37, 1713-1725.

24 (a) T. J. Thomas and R. P. Messner, Nucleic Acids Res., 1986, 14, 6721-6733; (b) Y. G. Gao, H. Robinson and A. H.-J. Wang, Eur. J. Biochem., 1999, 261, 413-420; (c) M.-H. Hou, S.-B. Lin, J.-M. P. Yuann, W.-C. Lin, A. H.-J. Wang and L. Kan, Nucleic Acids Res., 2001, 29, 5121-5128.

25 (a) M. Saminathan, T. Antony, A. Shirahata, L. H. Sigal, T. Thomas and T. J. Thomas, Biochemistry, 1999, 38, 3821-3830; (b) D. McLoughlin, M. Delsanti, P. A. Albouy and D. Langevin, Mol. Phys., 2005, 103, 3125-3139.

26 (a) M. T. Jr. Record, C. F. Anderson and T. M. Lohman, Q. Rev. Biophys., 1978, 11, 103-178; (b) M. T. Jr. Record, M. L. Lohman and P. De Haseth, J. Mol. Biol., 1976, 107, 145-158.

27 A. Loregian, E. Sinigalia, B. Mercorelli, G. Palù and D. M. Coen, Nucleic Acids Res., 2007, 35, 4779-4791. 